\title{
El caso Ossorio durante el primer franquismo: secuestro y manipulación de la memoria rival como estrategia de control social
}

\author{
Rafael Caballero Ruano*
}

\begin{abstract}
RESUMEN
En el presente articulo abordaremos una de las estrategias más comunes del nuevo régimen franquista para consolidar el control sobre la sociedad española durante sus primeros años de existencia (1936-1955): el secuestro y/o la manipulación de la memoria de los vencidos a fin de hacerla desaparecer de la memoria colectiva. Para ello, recurriremos a la campaña de descrédito que sufre una figura representativa del bando republicano -el político democristiano Ossorio y Gallardo-, centrándonos en las razones y procedimientos más usuales del Estado

para neutralizar a dicho rival. Como colofón, presentamos ciertas claves para la recuperación de la memoria individual,

con especial atención a la localización de fuentes y a los obstáculos políticos de la actual coyuntura histórica.
\end{abstract}

PALABRAS CLAVE

Biografia. España. Siglo XX. Cultura política.

\section{ABSTRACT}

In this article we will deal with one of the most common strategies of the new Franquista regime in order to consolidate the control of spanish society during the first years of existence (1936-1953): the kidnapping and/or the manipulation of the defeated's memory to make her disappear from the collective memory. For this we will analyse to the discredit compaign of a representative figure of the republican band -the demochristian politician Ossorio $y$ Gallardo- and the more usual state's reasons and procedures to neutralize the aforementioned rival. Finally we will present some keys for the individual memory's recuperation, especially the source's location and the politician obstacles of the present historical context.

KEY WORDS

Biography. Spain. Twentieth Century. Political Culture.

* Profesor Enseñanza Media. Cantabria. 
"(...). En mucho tiempo no se medirá la vastedad del estrago, la profundidad de la desventura. No habrá nadie que se lo diga y se lo demuestre a las generaciones actuales. Los gananciosos borrarán cuanto pueda ensombrecer su triunfo. Los perdidosos, lo mirarán desde su desposesión politica y económica. Se tejerá una historia oficial, para los vencedores, y acaso una antihistoria, no menos oficial, para los proscritos. (...).»

Manuel Azaña ${ }^{\prime}$

\section{INTRODUCCIÓN}

Cuando Ángel Ossorio dedicó gran parte de su tiempo de exilio a dejar viva su "memoria" y contrarrestar lo que pudiera hacer en contrario la nueva dictadura de Franco ${ }^{2}$, es que debía tener pruebas de lo que le estaba ocurriendo a su "memoria» en suelo patrio. Por de pronto, indicio más que razonable de estas sospechas era la campaña de desprestigio que había pesado sobre sí a lo largo de toda la Guerra Civil. La especie más dolorosa es la que propalaba que sus tres hijos varones disfrutaban de situaciones de privilegio, alejados del peligro de la contienda - que, v. gr., "estaban cómodamente emboscados en la Embajada" de París-, cuando lo cierto es que estaban en diferentes frentes de batalla. Calumnias que, por reiteradas, comenzaban a dar sus frutos dado que la prensa extranjera las reproducía sin el menor ánimo de contraste y verificación; el mismo Ossorio nos legó un ejemplo paradigmático del caso:

"Cuando estalló la guerra, mi hijo menor, afiliado al socialismo moderado, pidió un puesto en el combate y le pusieron a conducir un automóvil. Cierto

Cuaderno de La Pobleta, 17 de junio de 1937 en AzAĨA, M.: Memorias políticas y de guerra. Vol. II. Barcelona: Crítica, 1981, 4, edic., p. 87.

a El mismo se encargó de dejar por escrito (Ossorio, A: Mis Memorias. Madrid: Tebas, 1975 , pp. 223-224) la labor literaria que habia realizado durante sus siete años de estancia en Argentina, ya como embajador (1938-1939) ya como exiliado (1939-1946), con el propósito evidente de recopilar información que pudiera utilizarse para una reconstrucción futura de episodios tan crispados como el de la Il $^{\mathrm{a}}$ República y el de la Guerra Civil. Uno de sus hijos confirma dicha intención: "Ocupó Ossorio su tiempo en el exilio en tratar de esclarecer con su pluma y su palabra, las mentes de quienes aún no tenian muy claro el problema español, exponiendo a la vez sus ideas politicas y sociales." (Carta de Álvaro Ossorio a Rafael Caballero, Villa Adelina (Buenos Aires). 16/02/1989). La consciencia (y el deseo) de convertirse en fuente para la construcción de la historia en el futuro se muestra en Ossorio a propósito del siguiente pasaje escrito tras una relación de obras editadas por la embajada española en París: «(...). Claro que no habiamos de ganar la guerra con letra de imprenta, pero sobre que la labor sirvió para iluminar nuestras conciencias. todas esas publicaciones, pletóricas de datos indisputables, han quedado para iluminar la Historia cuando la Historia se puede hacer." (Ossonio, A.: La España de mi vida. Barcelona: Grijalbo. 1977 , p. 180). 
día le enviaron a una comisión a Toledo y subió a la torre de la catedral para divisar desde alli el panorama. El fotógrafo de "El Socialista» le hizo una fotografía que, con la protesta de mi hijo, publicó el periódico al día siguiente. Al cabo de los meses los periódicos católicos de Paris y de Bruselas reprodujeron la estampa adornada con este epígrafe: “El hijo del embajador rojo, pilla y saquea la catedral de Toledo". Nada menos" ${ }^{3}$.

\section{El acierto de ligar las sospechas de unos indicios con la demostración} de unos hechos, el que Ossorio tuviera la certeza de que existía un proceso de difamación que iba, sin solución de continuidad, desde el mismo instante del alzamiento hasta su etapa del exilio, viene a constituirse en punto de partida de nuestro estudio. Como quiera que esa "certeza» tenía su fundamento en los “deméritos» que el jurisconsulto madrileño había ido acumulando desde el año 36, fijaremos inicialmente nuestra atención

\footnotetext{
La España de mi vida, p. 161. Para comprobar la situación de sus hijos en los diferentes frentes de batalla ver Op. cit. pp. 181-182 y Carta de Alvaro Ossorio a Rafael Caballero, Villa Adelina (Buenos Aires), 07-19/08/1988: “(...). Pero viendo que el asunto iba para largo, me presenté en el Ministerio de la Guerra para alistarme en mi calidad de alférez de Complemento. A partir de alli participé en las operaciones en distintas unidades de Artilleria, cuerpo al que pertenecia. Estuve primero como segundo oficial de una bateria de montaña en Guadarrama; luego, teniendo en cuanta mi especialización por haber hecho el servicio militar en artilleria antiaérea, me dieron el mando, ya como teniente, de un grupo de ametralladoras antiaéreas de protección del parque de aprovisionamiento de un regimiento de tanques en el que permaneci hasta fines de 1936 en que se produjo un hecho que interrumpió - temporalmente como se verá después- mis actividades militares: dada mi condición de licenciado en Derecho, asi como mis conocimientos de francés e inglés, fui requerido para integrar el desguarnecido Cuerpo Diplomático como primer secretario de la Legación de España en Holanda, circunstancia que aproveché para contraer mi primer enlace. Me hice cargo del puesto pero a los 6 meses me sentí un poco avergonzado por la buena vida que estaba llevando mientras se luchaba en España y renuncié al cargo, regresando a la peninsula para reincorporarme al ejército republicano, ocupando sucesivamente los siguientes puestos: jefe de una batería antiaérea en la playa de las Arenas de Valencia; jefe de otra en el Prat de Llobregat (Barcelona); $2^{\circ}$ jefe de una unidad más importante en el monte Carmelo (Barcelona); $2^{\circ}$ jefe de una moderna bateria aérea en Montjuich (en esta época, el 7 de noviembre de 1937, nace mi hijo Manuel); ascendido a capitán se me nombra jefe de la unidad; luego el director general de Defensa Antiaérea, general Enrique Jurado, me nombra su ayudante, lo que involucraba el puesto de jefe de la Plana Mayor del organismo. In este puesto me sorprende la caida del frente de Cataluña, prólogo del fin de la guerra, y paso a Francia por Le Perthous, pequeño pueblo fronterizo donde, por rara y feliz coincidencia me reúno con mis hermanos Manuel (fuera de edad militar y funcionario del gobierno) y Francisco, capitán médico y jefe de la Escuela de Sanidad del Cuerpo de Carabineros. Los tres nos salvamos de los campos de concentración por poseer sendos pasaportes extendidos con anterioridad». Este extracto, verificado por otras fuentes, prueba que las informaciones periodísticas eran infundios al servicio de una estrategia consciente contra el enemigo - por lo demás, muy frecuentes entre las facciones en lucha- y que en todo caso los ventajas de sus respectivas circunstancias - si por "ventajas" entendemos no estar en primera línea de batalla- emanaban de sus cargos u ocupaciones; no obstante, cabe presentar como un privilegio el que las dos nueras y los nietos de sus hijos mayores, "por graves motivos de salud", residieran en un pueblo próximo a Paris en el momento que Ossorio estaba dirigiendo la embajada española en Francia (La España de mi vida, p. 181).
} 
en las razones del régimen franquista para neutralizar a un adversario al que seguiremos, paso a paso, en su trayectoria política.

A continuación, examinaremos, con carácter de aproximación, las distintas modalidades represivas de que se valen los aparatos de poder político para anular la memoria del político demócratacristiano, no sin antes apuntar que constituian actuaciones - abundantes y comunes, personales y colectivas - en el marco de un proyecto de altos vuelos: la afirmación del creciente dominio sobre la sociedad española a lo largo de la guerra, y el subsiguiente fortalecimiento de su control durante el período subsiguiente.

Por último, cabe añadir una referencia sobre los efectos perniciosos que sobre la supervivencia de esta concreta memoria individual ha provocado la estrategia del Estado. Lo que no podía sospechar Ossorio y Gallardo es que el "régimen de excepción» que salía de la contienda civil iba a durar cuatro décadas; que sus esperanzas por rehacer la historia desde su prisma se habrian de topar con serios obstáculos que ya nada tenían que ver con la burda censura o el silencio vergonzante; o que el impacto de la "memoria oficial» iba a dejar tan honda huella sobre otros tipos de memoria (social, colectiva, culta, ...), que en la actualidad existe la necesidad de una urgente y laboriosa tarea de recuperación, aventura un tanto ingrata pero enteramente apasionante.

\section{RAZONES DEL RÉGIMEN FRANQUISTA PARA ANULAR LA MEMORIA DE OSSORIO}

El proceso de descrédito cabe, por consiguiente, remontarlo a los primeros meses del enfrentamiento bélico, cuando el político conservador decide apoyar la causa republicana a través de su intervención en los medios de comunicación:

"Colaboraba yo entonces en Ahora de Madrid y en La Vanguardia de Barcelona. Esgrimí la pluma no sé si como un látigo o como un puñal, defendiendo a la República y acometiendo a sus agresores. Fue entonces cuando me declaré republicano. ¡Qué menos podia hacer en servicio de las legítimas instituciones de mi patria!.

El presidente del Consejo, don José Giral, modelo de decencia y de valor, me pidió que hablase al pueblo desde la radio del Ministerio de la Guerra y lo hice explicando que me ponía al lado del Gobierno por ser cristiano, por ser abogado y por ser conservador. Los intelectuales antifascistas me pidieron que hablara a los pueblos de América por la radio comunista y también lo hice, dándoles una explicación histórica de los que estaba ocu- 
rriendo en España. Por este orden ejerci cuantas actividades me fueron dables" ${ }^{4}$.

A esta infatigable labor publicista - puesta de relieve en las docenas de artículos, declaraciones, discursos y entrevistas de los dos primeros meses de contienda-, le siguió una fugaz aportación diplomática en la Sociedad de Naciones, completando la delegación que iba a acompañar al ministro de Estado, a la sazón Álvarez del Vayo, al objeto de defender «los derechos evidentísimos de la República Española”. Con independencia de los nulos resultados obtenidos, Ossorio iba a destacar por la entrega a la institución ginebrina "de la Gran Sala de Consejos, pintada por el artista Sert", así como por un extenso discurso en la Asamblea con el que se ligaba la legitimidad del gobierno republicano y el sentido de la misma institución en que se hallaban, y "que fue interrumpido constantemente por las aclamaciones de los delegados" 5 .

Ya que la resonancia de su voz en una tribuna de tanto fuste propagandístico como la de Ginebra no tuvo los efectos esperados, se imponía una nueva colaboración con la República desde la asunción de responsabilidades diplomáticas. No era para menos pues el gobierno de Madrid carecia de personal leal suficiente para ocupar todas las embajadas. Dada la significación católica y conservadora de Ossorio, se le busca un destino afín donde pudiera medrar a favor de los intereses republicanos.

4 La España de mi vida, pp. 154-155. Otra versión del comienzo de su colaboración prorrepublicana, en la que se contienen los principales argumentos de sus artículos en Ahora (v. gr., "La palabra mágica", 29/07/1936; "La justicia", 18/8/1936; o "La verdad y la ilusión", 02/09/1936), en Mis Memorias : (...). Fue entonces cuando di en sus columnas mi primer grito de iviva la República! y cuando abandoné mi posición de monárquico sin rey para entrar categóricamente en las filas republicanas. No exigía menos una situación como aquella del mundo republicano, traicionado de modo imperdonable por los que estaban juramentados para defenderle. Ya esto era bas tante para sublevar la sangre de cualquier español, pero además la presión de los paises totalitarios, menoscabando la elemental del nuestro, hacia la situación vergonzosamente aherrojada y requería que al lado de los republicanos nos colocásemos cuantos sentiamos una minima devoción a la patria. Desde aquel momento no cabian distinciones, y ser español era la misma cosa que ser republicano." (p. 208).

5 Para la labor de Ossorio en Ginebra ver Ahora, 03/10/1936, 05/10/1936 y 13/10/1936 y La España de mi vida, pp. 155-158. La referencia a los "nutos resultados obtenidos" viene a cuento porque «las aclamaciones de los delegados" no se correspondian con los acuerdos entre pasillos dado que el organismo supranacional actuaba subordinado a los intereses de inglaterra, "e Inglaterra, gobernando despreciativamente a Francia, vivia adherida a Alemania y procuraba su triunfo por todo los medios"; de ahi que Ossorio confesara que "con el alma partida me marché de la que debiera ser sede de la paz y no era sino una mera delegación del Foreign Office." (Mis Memorias, p. 209). 
Y todo menos obtener algún favor político o económico es lo que alcanzó nuestro hombre durante su estancia en Bélgica. La guerra está avanzada y sus embates ya han hecho mella en la sociedad belga. No es extraño por ello que su servicio al frente de la embajada en Bruselas le hubieran valido la enemiga de las personas de orden, tanto dentro como fuera de España. "El estado de opinión aqui -había confesado a su amigo Azaña a cuatro meses del fatídico 18 de julio- no difiere del de España y de todo el mundo. Aristocracia, clero, ejército y un 80 por ciento de las clases medias, bárbaramente en nuestra contra sin reparar en medios" ${ }^{6}$.

El resultado de esa oposición se manifestaba por distintos conductos: escaso eco de su voz en prensa; fría acogida de los representantes del Estado (el rey Leopoldo, el primer ministro Van Zeeland y el Ministro de Asuntos Exteriores - socialista para más señas- M. Spaak), que pusieron obstáculos para la presentación de credenciales (sin escolta ni honores) y que estuvieron rehusando durante meses cualquier invitación del embajador con groseros subterfugios; y, por último, los diversos desaires de la Iglesia para con un embajador que, al fin y al cabo, era un acreditado democristiano: desde la no devolución de la visita protocolaria del Nuncio en calidad de decano del Cuerpo Diplomático, hasta la expulsión de unos sacerdotes españoles afectos a la República -que servirian para demostrar que los "rojos" no lo eran tanto-, pasando por la retirada de una corona republicana a la memoria del cardenal Mercier -figura impulsora de la Democracia Cristiana por la que Ossorio sentía gran admiración-por orden del Arzobispo de Malinas ?

En suma, un trato ultrajante, en las antipodas del dispensado a los «fascistas», y la impresión para Ossorio de que la batalla diplomática, esto es, la lucha por la representación legítima en el extranjero, pese a la gran movilización de la intelectualidad republicana en su favor, estaba constituyéndose en la primera gran derrota de su gobierno.

6 Carta de Ossorio a Azaña, Bruselas, 26/11/1936, Archivo Nacional de Cataluña, Biblioteca Figueras (a partir de ahora, A.N.C.). Extremo que se repite por la pluma de Azaña al reseñar la merienda que compartió con Ossorio en La Pobleta a mediados de junio de 1937 (Memorias politicas y de guerra. Vol. II, pp. 79-80). Ver el "maltrato belga" también en La España de mi vida, pp. 158-162. Sobre su labor propagandística anterior a la época de embajador en Bruselas, ver Telegrama de Ossorio a Álvarez del Vayo, Ginebra, 07/10/1936, A.N.C., Mis Memorias, pp. 208-209 y La España de mi vida, p. 154-157.

Los episodios descritos en Carta de Ossorio a Azaña, Bruselas, 26/11/1936, A.N.C.; AZAÑA, M.: op. cit., p. 80; y La España de mi vida, pp. 160-161. 
Esta sensación de derrota, que empero no deprimía los esfuerzos de Ossorio por cambiar la pugna de signo, se sustancia en una carta que envía a Azaña en diciembre de ese primer año bélico, donde le aconseja que salga de Montserrat a las trincheras y que haga omnipresente su figura simbólica porque "un conjunto de circunstancias, inevitables unas y evitables otras, está haciendo que rápidamente la República y los republicanos se borren de la memoria de los españoles". Además, el embajador madrileño justificaba la obligación de dicha decisión porque «la estupidez de los enemigos ha lanzado a la circulación la referencia de que $\mathrm{V}$. es prisionero de los anarquistas, ha intentado sin éxito fugarse dos veces y al fin lo ha conseguido la tercera, volando en un avión con rumbo a no sé qué Jauja donde lo va $V$. a pasar muy bien". Y lo que vale para Azaña vale para sus partidarios republicanos:

"Por ley de lógica, la volatilización de V. se ha ampliado a todos sus correligionarios. Marcelino hace muy bien hablando en América. Barcia es víctima de aquella suspensión de relaciones del Uruguay y espera aquí la solución del conflicto. Amós no tiene función concreta en España y prefirió ir a Marsella. Sánchez Albornoz y Zulueta han sufrido bastante en sus respectivas embajadas para buscar en París un punto de reposo. De Ruiz Funes no he sabido nada desde que salió del Gobierno pero supongo que también tendrá justificado su descanso. Y lo que digo de los dioses mayores puede aplicarse a las figuras subalternas. De manera que si no fuese por el magnífico Giral (a quien, por cierto, han fusilado estos días las agencias telegráficas) podría creerse que el partido republicano había traído la República y no había dejado de su existencia la menor huella” ${ }^{8}$.

En fin, el consejo epistolar de Ossorio sólo perseguía estimular la presencia combativa de los partidos burgueses ( «fuerzas estrictamente republicanas") para atemperar el eventual proceso de "socialización" que se estaba dando en el territorio controlado por el gobierno legítimo, dado que los "buenos representantes de una burguesia comprensiva" contribuirian con «el engarce con la tradición, el posibilismo y el sentido evolutivo de las trasformaciones fecundas".

Para el tema que nos ocupa, poco importa que la carta de Ossorio -en opinión fundamentada del mismo Presidente de la República"fuera infundada $y$, en la parte que se refiere a los republicanos, un

8 Carta de Ossorio a Azaña, Bruselas, 29/12/1936, A.N.C. 
poco calumniosa" ${ }^{9}$. Lo cierto es que Ossorio había caído fácilmente en la «trampa» de la "propaganda facciosa», admitiendo la reclusión de Azaña y la defección o inhibición de los republicanos al ejemplo de su jefe. Lo importante es que Ossorio erraba en su análisis del problema porque en el trecho que existia entre su embajada y España, los sucesos eran distorsionados por mor de un aparato de propaganda enemigo sumamente eficaz, tan eficaz, que estamos hablando de una amigo íntimo de don Manuel con el que a través de la correspondencia, el teléfono $y$, esporádicamente, el encuentro personal, podía resolver malentendidos y esclarecer rumores con suma facilidad. Lo que más llama nuestra atención, en definitiva, es que la estrategia de Ossorio para ganar su propia batalla diplomática estaba fundada en un error de información ${ }^{10}$.

Nos preguntamos por qué esta obsesión por aclarar el carácter heterogéneo del bando legítimo y no podemos por menos que acogernos a la explicación del éxito que en el imaginario colectivo tuvo la idea de que la lucha que se libraba en España era la del fascismo vs. comunismo. Esto podria explicar asimismo que Ossorio hiciera gala del citado error de información, dado que la percepción de la situación en Bélgica estaba condicionada por la atmósfera que se respira allá donde va, en la que sus hermanos de clase e ideología le niegan la legitimidad jurídica y la autoridad moral, cuando no reniegan de su persona y de su compañía tratándolo de elemento sospechoso, esto es, de “rojo». En el contexto de lucha de clases de esta década, la posición intermedia del democristiano Ossorio, que mantenía sus creencias políticas de "buena fe y con miras de

AZAÑA, M.: Op. cit., pp. 81-82. En el citado encuentro de mediados de junio, Azaña reprocha a Ossorio que atienda con ligereza a tales infundios - "Dos meses largos he estado durmiendo en Montserrat, hasta que me he hartado; pero ni un solo dia ha faltado de Barcelona, en mi residencia oficial, ni de recibir visitas y audiencias, no de recorrer los caminos, visitar pueblos, etcétera."- $y$, por consiguiente, rechaza la atribución de que "la desaparición de los republicanos" se deba "a mi ejemplo personal"; en todo caso, argumenta don Manuel no sin antes ofrecer nombres y datos concretos, la marcha o eclipse de los republicanos se debe a que "lo daban todo por perdido y tenian miedo a los rebeldes o a los revolucionarios, 0 a unos y a otros".

10 Cipriano Rivas CHERIF confirma los rumores que se extendieron en el extranjero con motivo de la elección de Montserrat como residencia particular del Presidente: “(...). El retiro del Presidente dio pábulo a la noticia difundida por el extranjero de que estaba prisio. nero o poco menos del Gobierno, que, por lo demás, mantenía con él trato tan distante. A los amigos de cierta representación como don Ángel Ossorio, tampoco les gustaba mucho ni poco lo que parecia inhibición del Poder, y asi me lo hizo saber sin ambages rivestro Embajador en Bruselas, sin duda y también para que yo se lo transmitiera al interesado, (...).) (Retrato de un desconocido. Vida de Manuel Azaña, Barcelona: Grijalbo, 1979, página 363 ). 
conservación social», fue un rotundo fracaso por incomprensión y lejanía de ambos extremos ${ }^{11}$.

Como denunciaba aquel periódico católico de Bruselas, "rojo" era aquel embajador español que había tenido "la osadía de hacer colocar una corona en la tumba del cardenal Mercier" y que "por fortuna, enterado a tiempo, el señor cardenal arzobispo subsanó el suceso haciéndola retirar inmediatamente'.». «Rojo» era el calificativo que Ángel Ossorio intentaba sacarse de encima a golpe de recepciones, fiestas, banquetes y exhibiciones de todo tipo, "para que no cundiese la especie de que éramos, como buenos 'rojos', unos desarrapados sin educación y sin hábito de comer a manteles». "Roja» era —en impresión primera de la mujer del presidente del gobierno Van Zeland-aquella gente que residia en la embajada española hasta que "no pudo disimular su asombro al ver que madre (esposa del embajador) era tan distinguida como ella, que yo (hija del embajador) habia aprendido el inglés en el mismísimo Londres y que los rojos éramos gente civilizada". Y "rojos" eran aquel embajador español y su hija, aunque no se les notara en la presentación de credenciales ante la gran duquesa de Luxemburgo, puesto que supieron cumplir perfectamente las reglas del protocolo (no dar la espalda en la despedida y saludar $\sin$ el guante derecho) ${ }^{12}$.

La defensa pública del carácter heterogéneo del bando republicano —que continuó alegando durante su estancia en París, ya sea para combatir al enemigo ya para sostener su razón burguesa-, condenaría a Ossorio a una campaña de difamación, si cabe, más insistente. Cuanto más insiste Ossorio en sus postulados más es intoxicada la opinión pública extranjera como lo demuestra que a lo sustancial de su nuevo cometido - trasmitir al gobierno fran-

11 Esta reflexión, con la lucidez y soltura que le es característica, la puso de manifiesto Manuel Azaña en febrero de 1936 al referirse a otro eminente democristiano, Giménez Fernández: "(...). Estos cristianos sociales reeditan la posición de Ossorio hace veinte años, rigurosamente fracasada. En España lo 'cristiano' es especificamente católico. Lo social, en cuanto sale de academias y ateneos (a veces, sin salir) y abarca los intereses vivos de las clases, es anticatólico. $Y$ el catolicismo militante es acérrimo defensor del orden establecido. No sé cómo pueden conciliarse en una política ambas tendencias. Quien la mantenga de buena fe y con miras de conservación social, está destinado al fracaso y la soledad, sobre todo entre las clases conservadoras. Porque las otras, ni siquiera lo oyen." (Memorias politicas y de guerra. Vol. II, p. 20).

2 Las citas en Carta de Josefina Ossorio a Rafael Caballero, Buenos Aires, 22/10/1988; Carta de Josefina Ossorio a Rafael Caballero, Buenos Aires, 15/10/1988; La España de mi vida, pp. 160-181. 
cés que debía aprovechar la circunstancia de que todavía las instituciones españolas estaban en sintonía con la democracia y república galas- ${ }^{13}$ se le responda con la oposición de los grupos de presión más poderosos (ejército, aristocracia, alta burguesía, clero, partidos conservadores), a los que esta vez habría que sumar una numerosa población rural, temerosa de que la intervención en España condujera a una nueva guerra contra Alemania ${ }^{14}$.

Por otra parte, la importante tarea de convencer al gobierno francés para que respetara la libertad de comercio y de tránsito, así como el cumplimiento de los tratados firmados con anterioridad a la guerra, estaba siendo combatida en el seno del Comité de No Intervención, y su actividad de publicista y editor estaba siendo combatida en el mismo terreno. Recordemos, en este dirección, los bulos reiterados en prensa a que estuvo condenado, y de los que huelga aportar más ejemplos. Quedémonos con un sólo detalle: Ossorio considera que su tarea más útil en esta época debía consistir en "operar cerca de la masa social, procurando mantener la adhesión de las clases populares y esforzándose en despejar las tinieblas en los cerebros de la mesocracia, completamente desorientada e ignorante de la verdad" 15 .

Motivos no faltaron a los rivales de Ossorio para proseguir su táctica de acoso a partir de mayo de 1938. En la legación argentina, el embajador iba a irritar una vez más a sus enemigos con una nueva campaña proselitista que tiene sus ejes fundamentales en la estrategia de identificar los destinos de España a los destinos de Europa - con más motivo, después de 1939-, y en el elogio al denostadísimo Azaña en artículos que publicaba en la prensa bonaerense (más tarde en sus textos autobiográficos), con cierto éxito de audiencia entre los círculos más selectos (literatos, profesores, editores y periodistas) ${ }^{16}$.

13 Este nuevo cometido, idea personal del Sr. Azaña, en Azaña, M.: Op. cit., p. 310. La prueba más palpable de esa sintonía - argumenta el mismo Azaña - es que su cargo, la Presidencia, estaba ocupada por una personalidad republicana, pequeño burguesa y francófila para más señas.

14 Sobre la oposición de la población rural ver Mis Memorias, p. 213 y sobre la oposición de la oligarquía francesa ver La España de mi vida, p. 167.

15 La España de mi vida, pp. 179-180. En estas páginas se presenta una muestra significativa del tipo de obras que publicaba la embajada: Yo he creido en Franco. de F. Gonzálbez; Lo que han hecho en Galicia, Asi asesina la Falange, de Gabarain; Le pronunciamiento de 18 juillet 1936. dl profesor Sarrhaill; La rébellion militaire en Espagne, por Ceferino González; etc. Sobre sus funciones principales en la embajada, ver La España de mi vida, pp. 184-187.

16 Carta de Azaña a Ossorio, Pyla sur Mer, 19/01/1940, A.N.C. El remitente agradece la labor de defensa de su figura en tierras australes, aunque le advierte que su valentia le valdrá 
Añadamos, por último, al Ossorio del exilio, ese que ministro sin cartera del gobierno republicano quería cumplir con su promesa al Presidente de la República, cuando a su paso por Pedralbes camino de ultramar, le afirmó que seguiría luchando contra el militarismo sedicente tras la derrota ${ }^{17}$. Si la persecución de la imagen, palabra, recuerdo y personalidad de Ossorio era debida en parte a su adhesión incondicional al "monstruo Azaña», ¿qué decir de la reivindicación de la figura del presidente de la Generalitat en su obra Vida y sacrificio de Companys (1943) tras ser fusilado en Montjuich? Las razones para la persecución se agolpaban, siendo la más preocupante el que Ossorio estuviera dotando de autoridad moral al bando vencido por su condición de conservador y católico. Para colmo, era un «hombre de derechas» que, apoyado en su prestigio de "grande del foro», estaba desafiando las fronteras ideológicas atacando las instituciones de orden en España, ya sea impartiendo cursillos como aquel de cinco conferencias titulado Orígenes próximos de la España actual (De Carlos IV a Franco), cuyo objeto era "un furibundo ataque al militarismo español", ya sea defendiendo en las tribunas e imprentas de Argentina, Chile, Uruguay o Bolivia, lo que en 1940 escribió a Azaña sobre el catolicismo español:

"Coincido con $V$. en que hay muchos sacrificios inútiles y en que especialmente lo es el de la misa. La casi totalidad de los que asisten a ella, nutren el copiosísimo censo de los imbéciles, de los malvados y de los criminales. a los nombres de Gomá y Segura que $V$. invoca, me permitirá $V$. añadir los de los demás Obispos españoles. No obstante el laicismo de $V$. me autorizará a seguir creyendo en Dios, en sus mandamientos y en la moral cristiana que todavía sigue siendo lo mejor que se ha dicho por este pícaro mundo. (...) ${ }^{18}$.

curiosamente la oposición de las gentes de su propio bando: «(...). Pero es usted un valiente. ¿No sabe usted que, según la doctrina oficial consignada en la última acta de la Diputación de Cortes, con el silencio aprobador de los republicanos presentes, la guerra se ha perdido por culpa mia? Hablando de mi con afecto y consideración, es usted un hereje". Ossorio, por su parte, llega a ofrecer sus servicios para organizar un viaje desde Francia (Montauban) a la República de Argentina (Carta de Ossorio a Azaña, Buenos Aires, 09/08/1940). Para comprobar los términos de la defensa de Azaña ver Mis Memorias, pp. 201-203 y La España de mi vida, pp. 149-154

Carta de Ossorio a Azaña, Buenos Aires, 23/02/1940. Al decir de Angel Ossorio, la lucha por la causa republicana iba a continuar en el exilio, incluso con la esperanza de que el sacrificio de los vencidos habria de fructificar algún día: "Por de pronto creo que estamos reconquistando América. Claro que no por la obra de los políticos pero si por la de los estudiosos y de los técnicos. Yo creo que la labor de los Giral, González de la Calle, Victorio Macho, Díaz Canedo, Salvador, Jiménez Asúa, Bejarano, Cuatrecasas, Mira, Serrano Plaja, Casona, Sánchez Covisa, Bergamin, Fernández de los Rios, Ots Capdequi, Pi Suñer, Xirgú, Gutierrez Abascal y otros, no será imútil y está abriendo surco. Probaremos una vez más que somos maravillosos para las obras individuales e incapaces para las de conjunto".

${ }^{18}$ Carta de Ossorio a Azaña, Buenos Aires, 23/02/1940, A.N.C. Sobre la acusación al «militarismo" de los males que aquejan a España, ver Ossonio $>$ Gallardo, A.: Origenes próximos de la 


\section{PROCEDIMIENTOS DEL RÉGIMEN FRANQUISTA PARA ANULAR LA MEMORIA DE OSSORIO}

Para evitar que un hombre como Ossorio pudiera tener un cierto éxito de audiencia a partir de abril de 1939 y que, por ejemplo, su figura pudiera desmoronar el estereotipo de identificar el bando vencido con el «demonio rojo", el nuevo régimen iba a tomar una serie de medidas que, por activa y por pasiva, estaban destinadas a enturbiar, difuminar o borrar su memoria.

Por de pronto, como colofón a los esfuerzos de descrédito, se divulgará la maledicencia de que el ex-embajador madrileño "poseía en Buenos Aires una finca magnifica en la que vivia regiamente" o, con connotaciones racistas consubstanciales a los movimientos fascistas, que "era el jefe de los judios israelitas", por no hablar de que su "mujer era una poderosa dama india». Simultáneamente, el Colegio de Abogados de Madrid, del que fue decano entre 1930 y 1933, dejando "una labor tan fecunda y brillante», “le declararía proscrito". Y la Dirección General de Seguridad solicitaba a Salamanca, al archivo que se estaba creando con fines represivos, el correspondiente expediente que certificara su afiliación a algunas de las logias masónicas que funcionaban en España ${ }^{19}$.

Como quiera que los resultados de esta indagación fueron negativos, a Salamanca también iría el archivo personal de Ossorio, no sin antes requisar su biblioteca de treinta mil volúmenes por un juzgado de Responsabilidades Políticas ${ }^{20}$. Si ésta pasó al Colegio de Abogados sin dificultades, la confis-

España actual (De Carlos IV a Franco). Buenos Aires: Editor Aniceto López, 1940, pp. 235-237. Sobre la promesa de seguir luchando en su despedida camino de Buenos Aires, ver AzAÑA, M. Op. cit., pp. 396-397. Sobre la defensa que Ossorio hace de las figuras de Azaña y Companys, no olvidemos que fue el abogado defensor de ambos por los sucesos de octubre de 1934.

19 Para la petición de afiliación masónica ver su expediente en Archivo Histórico Nacional (Sección Guerra Civii), Salamanca. Para la proscripción en el Colegio de Abogados de Madriơ, SANCHEZ RocA, M.: Angel Ossorio, abogado de la abogacia. La Habana: Editorial Lex, 1946, p. 13. Sobre su obra fecunda en dicha institución ver La España de mi vida, p. 237 y Mis Memorias, pp. 195-197. Sobre las calumnias Mis Memorias, p. 222.

20 Carta de Alvaro Ossorio a Rafael Caballero, Villa Adelina (Buenos Aires), 7-19/08/1988: "Nada sabia acerca del incendio de que me habla, como tampoco de la existencia de legajos de nuestro padre en el Archivo Histórico Nacional de Salamanca. Siempre fue una incógnita para nosotros 10 que hubiera podido suceder con tales legajos y otros papeles que quedaron en la casa de Madrid al comienzo de la guerra civil. Sólo supimos que el Colegio de Abogados había hallado la biblioteca formada por nuestro padre a través de 63 años de vida y 40 de actividad profesional, en un juzgado de Responsabilidades Políticas. Dicha biblioteca -compuesta por más de 30.000 volumenes - fue trasladada al Colegio previa solicitud de su decano al juez. Años más tarde aquella institución decidió legalizar de pleno derecho la posesión de tan valiosa biblioteca y el decano, don Antonio Pedrol Rius, se puso en contacto con nosotros para informarnos del hecho; 
cación del archivo respondía a una doble intención, que obviamente compartiría con toda la documentación (particular, partidista, sindicalista, institucional) que allí se había ido almacenando en el transcurso de la guerra: hallar información comprometedora que pudiera utilizarse en detrimento de la imagen de Ossorio y en represión de los elementos republicanos que hubieran estado en contacto con él; y hurtar al público el acceso a las fuentes de la otra España, aportando mayor seguridad a la versión oficial de los acontecimientos.

A esa "Historia Oficial», destinada a abrillantar el triunfo glorioso a costa de una "antihistoria oficial», dirigida a "borrar todo cuanto pudiera ensombrecer" el panorama, contribuirían productos culturales de cuño oficialista. Para muestra un botón significativo: al buscar lo que la célebre Enciclopedia Espasa-Calpe dice de nuestro hombre, hallamos un trato diferenciado en los tomos que se publican antes y después de la guerra. Si en la primera edición de 1919, los términos del texto son, cuando menos, elogiosos, participando de ello el que en ese mismo año llegara Ossorio a ser Ministro de Fomento de un gobierno Maura; y si la siguiente aparición (1932) coincide con pleno bienio reformista, donde el papel de Ossorio ha estado en sintonía con el nuevo régimen y, por consiguiente, los contenidos textuales vuelven a ser positivos para su imagen; en 1953, en cambio, hay una revisión de su labor, con términos claramente censurantes, e incluso tergiversadores de la realidad. Atribuir al prócer madrileño la autoría de la Constitución de 1931 no deja de ser una incorrección comprensible, por cuanto Ossorio llegó a presidir la Comisión Jurídica Asesora que tenía encomendada la elaboración de un Anteproyecto de Constitución, aunque éste fuera finalmente rechazado; pero atribuirle el ataque a la Iglesia contenida en dicha Constitución, cuando fue de las escasas voces defensoras de los derechos - y hasta de los privilegios- de la misma, no parece sino una maniobra de burda manipulación ${ }^{21}$.

mi hermana y yo, únicos herederos supervivientes, le contestamos para hacer donación de la biblioteca, por cuanto considerábamos que en ningún lugar podria estar mejor, dado que nuestro padre habia sido también decano del Colegio de Abogados. (...).".

Diccionario-Enciclopédico, Madrid: Espasa-Calpe, 1919, n40, p. 919; Op. cit., 1932, Apéndice 7, p. 1434; y Op. cit, 1953, Suplemento 1945-1948, p. 386. El valor indiscutible de este ejemplo se halla en que "errores" contenidos en esta enciclopedia de prestigio -para muchos el único depósito del saber - seguirán vigentes por mor de una costosa revisión bibliográfica. “Justo» es decir que la versión enciclopédica abreviada de la misma editorial, publicada en años de pleno franquismo (mediados de los cincuenta), despacha la voz de “Angel Ossorio y Gallardo" con una asepsia digna de encomio... si no fuera porque no contiene nada relevante, y nada está contextualizado en un tiempo histórico: "Jurisconsulto, diplomático y político español (1873-1946). Fué presidente del Ateneo de Madrid y de la Real Academia de Jurisprudencia. Ocupó altos cargos políticos y publicó notables obras juridicas." (Diccionario-Enciclopédico Abreviado. Madrid: EspasaCalpe, 1955, Tomo VI, p. 124) 


\section{CONCLUSIONES}

Pese al carácter incipiente del presente estudio, podemos adelantar unas pocas conclusiones, con las lógicas reservas de un resultado provisional, a las que adjuntaremos una hipótesis de trabajo como futura línea de investigación.

4.1. En primer lugar, hemos querido mostrar las diversas tentativas de la Memoria Oficial -entendida ésta como la que emana de las instancias del Estado e «intenta la glorificación, la mitificación o, en otros casos, la ocultación para elaborar, propagar y mantener una identidad y una memoria 'nacionales',- ${ }^{22}$ con el fin de borrar una memoria individual de la memoria colectiva. Tales tentativas deben ser insertadas en un proceso caracterizado por un distinto grado de vigilancia y persecución en función de la evolución política de la Dictadura, hasta el punto que pasada la década de los cincuenta, alejados los peligros que amenazaban la supervivencia o el desarrollo del régimen franquista, observamos una recuperación parcial, limitada e inofensiva, de la figura analizada ${ }^{23}$.

4.2. Es verdad que nos hemos extendido más en las razones de la Dictadura para neutralizar a Ossorio (v. gr., legitimación del adversario vencido por su credo político) que en las formas de neutralización de la memoria individual ${ }^{24}$, pero también es verdad que las evidencias presentadas, con independencia del grado de aplicación, informan de un aparato ideológico-represivo con la inequívoca vocación de anular al contrario. Es decir, para construir un nuevo régimen, el bando vencedor de la guerra civil no ahorrará esfuerzos para llevar a cabo las más variadas estrategias de control: desde la difamación más descarada a la confiscación de los bienes, y desde el uso interesado de la información en medios de pres-

22 CuESTA, Josefina: Historia del presente. Madrid: Eudema, 1993, p. 44

23 Esto es lo que señalan dos obras escogidas a voleo de nuestra biblioteca, publicadas ambas en 1970: uso biográfico y anecdótico de la figura de Ossorio en PEMAN, J. $\mathrm{M}^{\mathrm{a}}$ : $\mathrm{Mis}^{\mathrm{a}}$ almuerzos con gente importante. Barcelona: Dopesa, 1970, pp.69-71 (capitulo «Con Ossorio y Gallardo y Azorín"); utilización parcial de opiniones sueltas de Ossorio para ilustrar imágenes, acontecimientos e ideas en ArRaras, J.: Historia de la Segunda República Española. Madrid: Editora Nacional, 1970,4 tomos.

24 Correspondiente a los sujetos de una sociedad, entendemos por "memoria individual" la "reconstrucción psiquica e intelectual que comporta una representación selectiva del pasado" hecha por un solo individuo. Emerge cuando se le estimula con preguntas y se contrasta con otras experiencias individuales. Constituye "el soporte, producto y exponente primario" de otro tipo de memorias — v. gr., colectiva y social-. Por su carácter "social" -tanto en la experiencia intersubjetiva de rememoración como en el carácter del lenguaje y de sus contenidos, comunes a otros individuos - se convierte en frecuente objeto de análisis a través de un nutrido conjunto de fuentes -entrevista, encuesta, video, memorias escritas- (CUESTA, J.: Op. cit., pp. 41-42). 
tigio ( $v$. gr., el caso de la Espasa-Calpe) al silencio más absoluto que se deriva del "cerrojazo» a un archivo personal. Sin olvidar que esta labor orientada hacia un solo hombre debía considerarse dentro de un contexto más amplio, cual es la persecución de los vencidos en su conjunto, también hubiéramos podido incluir la reclusión o/ y la eliminación física de nuestro personaje si no se hubiera dado el caso de que el final de la guerra sorprendió a Ossorio muy lejos del territorio nacional ${ }^{25}$.

4.3. Cabe contemplar con satisfacción que una memoria individual puede ser recuperada gracias a la supervivencia de otras memorias individuales, incluso en el caso de que aquella no hubiera dejado rastros ${ }^{26}$. En nuestro caso, sin embargo, el interesado iba a dejar nítidas huellas de su existencia y sólo faltaba que desapareciera el obstáculo que supone la pervivencia del mismo régimen político para que emergiera con fuerza, al lado de los variados y múltiples testimonios del "exilio interior», las fuentes más sobresalientes del legado de Ossorio y Gallardo: la publicación española en los años 1975 y 1977 de «Mis Memorias" y "La España de mi vida", respectivamente.

En esa operación de importación, el investigador podrá acudir a otras fuentes que ayudan a mantener viva la memoria individual e incluso a engrosar el bagaje de una determinada memoria colectiva - la del exilio- ${ }^{27}$, así como rastrear memorias individuales por medio de las técnicas y métodos de la Historia Oral. Nuestra modesta aportación consiste en la con-

25 Extremo admitido por el mismo Ossorio en sus memorias: “(...). En realidad ésta (su paso de Francia a Argentina)fue mi salvación, porque si me llegan a dejar en Paris a estas horas habria sido yo preso y fusilado como mi desventurado amigo Luis Companys. (...)." (Mis Memorias, $p$. 216). Los casos de Companys y Peiró avalaban tal razonamiento (SUTHWORTH, H. R.: El mito de la Cruzada de Franco. Barcelona: Plaza y Janés, 1986,p. 177)

26 Posiblemente el mejor punto de partida para la recuperación de la memoria de Ossorio sea la semblanza que realizó su amigo Azaña en el Cuaderno de La Pobleta, 17 de junio de 1937 en Memorias politicas y de guerra. Vol. II, pp. 84-85. Con motivo del ya mencionado encuentro personal que tuvo lugar a mitad de junio de 1937, el Presidente se explaya a gusto aportando, al decir de sus hijos, "un acertado retrato de nuestro padre" (Carta de Alvaro Ossorio a Rafael Caballero, Villa Adelina (Buenos Aires), 16-25/02/1989). Notemos la importancia que el autor presta a su figura -aunque sólo sea en el orden de las relaciones personales- y destaquemos cómo Ossorio queda bien parado ante la aplicación de un bisturí tan implacable como la pluma del Presidente.

2. ¿Qué se hacia desde el bando republicano en respuesta al ataque que Ossorio recibió del enemigo? En los meses posteriores a su muerte, organizar homenajes póstumos como el acto reivindicativo del Colegio de Abogados de La Habana, que, plasmado por escrito en la obra de Mariano SANCHEZ ROCA: "Ángel Ossorio, abogado de la abogacía", iba a contener el discurso-panegírico pronunciado el 20 de noviembre de 1946 y compuesto en su mayor parte con información de las obras autobiográficas de Ossorio. No olvidemos además la publicación de sus libros, sobremanera las de carácter jurídico ( $v$. gr., "El alma de la toga" llegó a una $7^{\text {a }}$ edición argentina con motivo del 25 aniversario de su muerte) 
tribución epistolar de la memoria de los hijos vivos de Ossorio, aunque su estado de avanzada edad ha mermado las enormes potencialidades ${ }^{28}$. Potencialidades que han sido compensadas por la sola referencia a la localización del archivo personal del Ossorio-embajador y del Ossorio del exilio.

Por último, la recuperación de esta memoria individual debe fijarse en el descubrimiento de archivos, privados o públicos, con documentación particular o institucional, que han estado siempre ubicados en España. Tal es el caso del Archivo personal correspondiente a la época de la II ${ }^{a}$ República en el Archivo Histórico Nacional de Salamanca, o la abundante documentación existente en la Fundación Maura con que Javier Tusell/ Juan Avilés y Ma Jesús González han podido incorporar al Ossorio de la Restauración para realizar sus obras sobre el movimiento maurista. En fin, la recomposición de las pistas de un hombre público no puede pasar por alto un repaso a las fuentes hemerográficas ${ }^{29}$, máxime cuando don

28 La importancia de la hija soltera de Ossorio, su secretaria personal durante 34 años, hacia imprescindible un cruce de cartas para saber de primera mano información velada en la documentación escrita, pero la mala salud vinculada a su avanzada edad (88 años) interrumpió las escasas dos epístolas que nos envío. Nos consta, empero, que estaba escribiendo un libro de memorias y que ha dejado testimonio grabado por medio de una investigadora española. Preocupaba a nuestra informante que pudiera interesar su narración, infravalorándose como fuente de información y, en consecuencia, coartando las posibilidades de tal fuente oral.

Las dos cartas (Carta de Josefina Ossorio a Rafael Caballero, Buenos Aires, 15/10/1988 y Carta de Josefina Ossorio a Rafael Caballero, Buenos Aires, 22/10/1988) complementan la información que suministra la obra del padre con datos elegidos con capacidad discriminatoria por cuanto Josefina Ossorio deseaba contar su experiencia intransferible, a la vez que no quería repetir lo "ya sabido". De ahí, ese toque tan "personal» que en la primera carta se traduce en una relación minuciosa de las personas que les rodearon en Bruselas, y en la segunda por la sorprendente recuperación de los detalles con que se realizó el proceso de adopción en el extranjero del primer contingente de niños españoles. Datos muy puntuales como los relativos a la familia Garcia Lorca o el recuerdo de su paso por Luxemburgo, hacen que la anécdota posea un valor de estímulo para el investigador y un indicio de que la remitente posee mucha más información de la que, con evidente prejuicio, cree.

Por su parte, las cartas del hijo menor de Ossorio dan fe de la labor política que Ossorio desplegó en la Argentina, en cuyo radio de acción se encontraban otros paises del cono sur, y de la división de fuerzas en el seno de la sociedad argentina y entre los inmigrantes españoles con respecto a la guerra civil.

29 El Eusko Deya (La voz del pueblo vasco), periódico parisino publicado por el gobierno vasco a partir del 31 de diciembre de 1936, resulta un magnífico escaparate para estudiar en profundidad esa obsesión (v. gr., "Por qué algunos católicos españoles no se han rebelado", 11/02/1937 y 14/02/1937; o BEAGAMIN, José: "Opinios catholiques. Los que no nos hemos rebelado", 28/03/1937) de los católicos por distinguirse de entre el magma republicano. Las actividades e ideas de Ossorio serán tratadas con abundancia y toda suerte de detalles (v. gr., "M. Ossorio y Gallardo. Un grand leader catholique vous parle", 10/01/1937; "En la Maison de la Chimie. Conferencia del Sr. Ossorio y Gallardo", 25/02/1937; u OssoRio, Ángel: "Leeme, te lo ruego. A un militar del otro lado", 02/06/1937). 
Ángel, con fidelidad a sus raíces y formación, demostró una intensa vocación periodistica.

4.4. Debemos ser consciente de la intensa influencia que la Memoria Oficial puede ejercer sobre la memoria culta ${ }^{30}$, hasta el punto de llegar a fenómenos de olvido o tergiversación de la realidad. Si como hemos comprobado, este hecho adquiere caracteres graves dentro de los sistemas políticos autoritarios, no es menos grave que se produzcan con sistemas democráticos dado que, a diferencia de los primeros, las causas del olvido o de la tergiversación son más difíciles de detectar.

En el abandono de la memoria de Ossorio en nuestro país - iy ahí están intocables sus dos archivos particulares para demostrarlo!- ${ }^{31}$, han influido a la par dos factores de índole política y cultural: $1^{\mathrm{a} /}$ la ausencia de una reivindicación de su figura, a diferencia de sus admirados Maura y Azaña, que debe vincularse al fracaso de la opción democristiana en España; y $2^{a} /$ la tendencia a montar la investigación histórica en torno a las celebraciones y conmemoraciones, (esto es, en torno a la subvención económica y, a la postre, al interés político de coyuntura), hurtando al estudio del sosiego y tiempo suficientes para afrontar el análisis en profundidad - ino sin antes inventariar y clasificar la información!--, de archivos tan fecundos.

No es, pues, requisito indispensable el que "se hayan calmado las pasiones" derivadas de aquel estigma de la guerra, para que - como quería el mismo Ossorio- se pudiera establecer "la verdad de que los republicanos españoles que vivimos aquí refugiados fuimos un puñado de hombres de bien que dejamos patente el ejemplo de nuestra limpia conducta y nuestra honradez inmaculada" - ${ }^{32}$, sino que es necesario un proceso de desvinculación de la Historia respecto a la coyuntura política del momento.

30 En acepción de Josefina Cuesta (Op. cit., p. 44), la «memoria culta" es la recogida y transmitida por los historiadores con la doble acción de desmitificar el contenido de otros tipos de memoria e influir sobre las mismas.

${ }^{31}$ No podemos considerar una recuperación de la memoria de Ossorio, su aparición frecuente en las obras sobre el maurismo (v. gr. TUSELL, J./ AVILÉS, J.: La derecha española contemporánea. Sus origenes: el maurismo. Madrid: Espasa-Calpe, 1986 ; y GonzÁlEZ, Ma J.: Ciudadanía y acción. El conservadurismo maurista, 1907-1923. Madrid: Siglo $x \times 1,1990$ ) porque $\left.1^{\circ}\right)$ tratan del primer Ossorio; $2^{\circ}$ ) Ossorio no es el protagonista, sino un punto de referencia con el que se miden las posiciones de Maura y otros mauristas; y $3^{\circ}$ ) no utilizan fuentes de su archivo personal, sino documentación parcial contenida en el archivo de don Antonio Maura. Por su parte, la obra de Javier TUSELL sobre la Democracia Cristiana (Historia de la Democracia Cristiana en España. Vol. II. Madrid: Sarpe, 1986, $2^{\beth}$ edic., pp. 200-227) supone una pequeña excepción a la regla, aunque padece un examen superficial de las fuentes contenidas en el Archivo Histórico Nacional de Salamanca.

${ }^{32}$ Mis Memorias, p. 224 
En esta dirección, sería bueno que alguna vez nos dejáramos dirigir por los propios protagonistas de la Historia para empeñarnos en la grata tarea de recuperar la memoria individual y colectiva de nuestro pueblo. Sería bueno que, por una vez, en atención y respeto a los ascendientes que actuaron con buena voluntad, en busca de la honradez que se desprende del «intento» de liberarnos de las ataduras del entorno más netamente individual e inmediato y de sintonizar con las sensibilidades del pasado, atendiéramos a las súplicas de los protagonistas más lúcidos de nuestra Historia y convirtiéramos en objeto de estudio la concreta preocupación de Azaña con respecto al fenómeno del exilio y a la pérdida de memoria... tanto de los descendientes de Ossorio como del mismo Ossorio:

"Me interesan las noticias que me da usted respecto de algunos emigrados, aunque no por igual, porque no todos han merecido por su conducta el mismo aprecio. Lo que primero y más hondamente me conmueve es el destino de las víctimas anónimas, que ni siquiera pueden consolarse con la vanidad de decirse representantes de una gran causa perdida injustamente. El soldado que sin zapatos ni ropa (también sin jefes ni material) aguantaba la guerra en las sierras españolas; el desvalido que andaba tres leguas para cortar un manojo de hierbas con que engañar el hambre; el señor, caído en mendiguez, que hurgaba en los cubos de basura en Barcelona, buscando un mendrugo... Estos son los primeros. $Y$ ya sabe usted donde han ido a parar, dentro o fuera de España. Después, podemos poner a los estadistas, a los oradores, a los caudillos, etc. Creo que usted compartirá mi preferencia; porque para algo es usted madrileño, y llevaba capa (yo también), y hemos recibido, uno y otro, el aire del pueblo. (...)»33.

33 Carta de Azaña a Ossorio, 19/01/1940, Pyla sur mer a Buenos Aires, ANC. 